\title{
Crack Extension in Hydraulic Fracturing of Shale Cores Using Viscous Oil, Water, and Liquid Carbon Dioxide
}

\section{$\operatorname{AUTHOR}(S):$}

Bennour, Ziad; Ishida, Tsuyoshi; Nagaya, Yuya; Chen, Youqing; Nara, Yoshitaka; Chen, Qu; Sekine, Kotaro; Nagano, Yu

\section{CITATION:}

Bennour, Ziad ... [et al]. Crack Extension in Hydraulic Fracturing of Shale Cores Using Viscous Oil, Water, and Liquid Carbon Dioxide. Rock Mechanics and Rock Engineering 2015, 48(4): 1463-1473

\section{ISSUE DATE:}

2015-06-12

URL:

http://hdl.handle.net/2433/201552

\section{RIGHT:}

The final publication is available at Springer via http://dx.doi.org/10.1007/s00603-015-0774-2.; The full-text file will be made open to the public on 12 June 2016 in accordance with publisher's 'Terms and Conditions for Self-Archiving':; This is not the published version. Please cite only the published version.; この論文は出版社版でありません。引用の際 には出版社版をご確認ご利用ください。 
Crack Extension in Hydraulic Fracturing of Shale Cores Using Viscous Oil, Water, and Liquid Carbon Dioxide.

Ziad Bennour ${ }^{1}$, Tsuyoshi Ishida ${ }^{* 1}$, Yuya Nagaya ${ }^{1}$, Youqing Chen ${ }^{2}$, Yoshitaka Nara ${ }^{1,5}$, Qu Chen $^{3}$, Kotaro Sekine ${ }^{4}$ and Yu Nagano ${ }^{4}$

${ }^{1}$ Department of Civil and Earth Resources Engineering, Graduate School of Engineering, Kyoto University, Kyoto, Japan

${ }^{2}$ Department of Energy Science and Technology, Graduate School of Energy Science, Kyoto University, Kyoto, Japan

${ }^{3} 3 \mathrm{D}$ Geoscience Inc., Tokyo, Japan

${ }^{4}$ Japan Oil, Gas and Metals National Corporation, Chiba, Japan

${ }^{5}$ Now he is working for Tottori University, Tottori, Japan

*Corresponding author: Tsuyoshi Ishida

Department of Civil and Earth Resources Engineering, Graduate School of Engineering,

Kyoto University, Kyoto Daigaku Katsura, Nishikyo-ku, Kyoto 615-8540, Japan

E-mail: ishida.tsuyoshi.2a@kyoto-u.ac.jp

Tel.: +81 75383 3209; Fax: +81 753833213 


\section{Abstract}

We performed hydraulic fracturing experiments on cylindrical cores of anisotropic shale obtained by drilling normal to the sedimentary plane. Experiments were conducted under ambient condition and uniaxial stresses, using 3 types of fracturing fluid: viscous oil, water, and liquid carbon dioxide $\left(\mathrm{L}-\mathrm{CO}_{2}\right)$. In the experiments using water and oil, cracks extended along the loading direction normal to the sedimentary plane under the uniaxial loading and extended along the sedimentary plane without loading. These results suggest that the direction of crack extension is strongly affected by in situ stress conditions. Fluorescent microscopy revealed that hydraulic fracturing with viscous oil produced linear cracks with few branches, whereas that with water produced cracks with many branches inclining from the loading axis. Statistical analysis of P-wave polarity of acoustic emission waveforms showed that viscous oil tended to induce Mode I fracture, whereas both water and $\mathrm{L}-\mathrm{CO}_{2}$ tended to induce Mode II fracture. Crack extension upon injection of $\mathrm{L}-\mathrm{CO}_{2}$ was independent of loading condition unlike extension for the other two fluids. This result seemed attributable to the low viscosity of L-CO $\mathrm{CO}_{2}$ and was consistent with previous observations for granite specimens that low-viscosity fluids like $\mathrm{CO}_{2}$ tend to induce widely extending cracks with many branches and with Mode II fractures being dominant. These features are more advantageous for shale gas production than those induced by injection of conventional slick water. 
Keywords: Anisotropy; Acoustic emissions; Shale; Hydraulic fracturing; Carbon dioxide; Viscosity 


\section{Introduction}

Shale gas refers to the natural gas trapped within formations of shale, a finegrained sedimentary rock that can be a rich source of petroleum and natural gas. However, since the low permeability of shale greatly inhibits the flow of gas from reservoir rocks to production wells, the economic viability of developing shale gas depends on effective stimulation of reservoirs. Recently, horizontal wells employing a multistage hydraulic fracturing technique have become the stimulation method of choice and proved successful in shale gas reservoirs (Arthur et al., 2008).

Hydraulic fracturing is the process of initiation and propagation of cracks by injection of a fluid at a pressure higher than the failure stress of the rock. The technique of hydraulic fracturing stress measurements was developed by Hubbert and Willis (1957). Building on this work, Cleary (1958) presented an early version of hydraulic fracturing theory and the possibility of fracture control. Since then, many theoretical and experimental investigations have been conducted (i.e. Zoback et al., 1977; Schmitt and Zoback, 1989; Haimson and Cornet, 2003).

Underground formations are subjected to complex stress fields and affected by various geological processes, as described by Amadei and Stephansson (1977) and Zang and Stephansson (2010). The magnitude and direction of the principal stresses are important in hydraulic fracturing because they control the amount of pressure required 
to create and propagate a crack, the direction of the crack and the crack shape. The direction that a crack induced by hydraulic fracturing takes in a rock is also a function of several variables, including anisotropy of rock strength. Sun et al. (2011) investigated crack extension during hydraulic fracturing in oil shale and found that the cracks are elliptical and that cracks extend along different directions due to anisotropic properties and the in situ stress condition.

Ishida et al. (2004; 2012; 2013) have previously conducted hydraulic fracturing experiments using carbon dioxide $\left(\mathrm{CO}_{2}\right)$, water, and viscous oil and found that low viscosity fluids such as $\mathrm{CO}_{2}$ tend to induce widely extending cracks with many branches. These cracks should be better suited for producing shale gas because they have a larger surface area within the shale than those induced by water.

Accordingly, by monitoring acoustic emissions (AE), this study focuses on the crack growth in shale cores in relation to the effects of stress condition and anisotropy due to sedimentary planes. This study also examines the effect of the viscosity of various fracturing fluids (viscous oil, water, and $\mathrm{CO}_{2}$ ) on the fracture mode and on the microscopic features of the induced cracks. The results of this study may be beneficial in industrial energy projects such as extraction of unconventional gas from shale and the sequestration of greenhouse gases. 


\section{Experimental methodology}

\subsection{Shale cores}

Experiments were performed on cylindrical shale cores measuring roughly 170 $\mathrm{mm}$ in length and $85 \mathrm{~mm}$ in diameter. All samples were retrieved by drilling blocks obtained from a depth of 275 m below sea level while mining a drift at the Kushiro coal mine in Hokkaido, Japan. The blocks were sandy shale from Palaeogene Harutori coal bearing formation. Because sedimentary planes were clearly observed on the surfaces of the blocks, the drilling direction was selected to be normal to the sedimentary plane.

A hole for hydraulic fracturing with a diameter of $10 \mathrm{~mm}$ was drilled in the side of the core at the vertical midpoint. A Cartesian coordinate system was applied to the cores: the $Z$-axis was set along the cylindrical axis and normal to the sedimentary plane, the $X$-axis was set along the drilled hole, and the $Y$-axis was set orthogonal to the other 2 axes, as shown in Fig. 1.

P-wave velocities were measured along the three selected axes for each specimen. The results of the P-wave velocity measurements clearly show orthogonal anisotropy due to the sedimentary bedding with the exceptions of those in the cores K-01 and Kc12 (Table 1).

\subsection{Uniaxial stress conditions}

Hydraulic fracturing tests were run at ambient condition and two uniaxial stresses of 1 and $3 \mathrm{MPa}$, applied along the Z-axis ( $\sigma z$, normal to the sedimentary plane). Four 
10-mm-long strain gauges were attached to the cores to confirm that loading was uniformly applied to the cores before testing.

\subsection{Fracturing fluid and pressurizing system for hydraulic fracturing}

Three types of fluids, namely, viscous oil, water, and liquid carbon dioxide (L$\mathrm{CO}_{2}$ ), were used for hydraulic fracturing. The viscous oil used was automobile transmission oil (Mahha Super Transmission Oil 75W-90; Fuji Kosan Co. Ltd., Tokyo, Japan). At the experimental temperature, the viscous oil was 270 times more viscous than water, whereas the $\mathrm{L}-\mathrm{CO}_{2}$ has about $1 / 10$ the viscosity of water.

A packer with a pressurizing section of $30 \mathrm{~mm}$ was set in the center along hole. Fluids were injected at a constant flow rate of $1 \mathrm{ml} / \mathrm{min}$, and injection pressure was recorded at $0.1 \mathrm{~s}$ intervals. A syringe pump with controllable discharge flow rate was connected to the hole via connecter pipes and used to inject the fluid. A pressure transducer was placed at a position close to the packer to detect the actual fluid pressure of the injection.

\subsection{AE monitoring system}

An array of 16 PICO sensors (Physical Acoustics Corporation), which were cylindrical, $3 \mathrm{~mm}$ in diameter, and $4 \mathrm{~mm}$ in length, with a resonance frequency of around $400 \mathrm{kHz}$, was used to record $\mathrm{AE}$ events. The detected AE signals were amplified by a total of $84 \mathrm{~dB}$ (36 dB in the pre-amplifier and $48 \mathrm{~dB}$ in the signal conditioner, 
except in experiments that used $\mathrm{L}-\mathrm{CO}_{2}$ as fracturing fluid, where signal conditioner was set to $24 \mathrm{~dB}$ due to a high level of noise), then recorded on a hard disk via an $\mathrm{A} / \mathrm{D}$ converter. For each event, the record length and sampling time of the A/D converter were selected to be 2048 words (each word size of 32 decimal digits) and $0.1 \mu \mathrm{s}$, respectively, with 12-bit resolution. The dead time was set to be $1 \mathrm{~ms}$ after recording an event to prevent the hard disk from recording too much noise due to the vibrations following a large AE event. Recording of an AE event was triggered when one of the signals from the 16 sensors exceeded $3 \mathrm{~V}$, and the triggered events usually have more than a few signals.

The AE events were monitored and recorded during the injection. Later in the process, the AE hypocenters were located by P-wave arrival time at sensors based on a least squares method and then compared to the results of visual detection in order to trace the shape and orientation of cracks induced on the surface of the cores.

Furthermore, the mode of fracturing was examined by the statistical analysis determining the polarities of P-wave initial motion along their respective AE waveforms following Zang et al. (1998) and Graham et al. (2010). Then, depending on their polarity, they were categorized as either compression or dilatation. The number of compressional initial motions and the number of dilatational were counted for each $\mathrm{AE}$ event. A ratio of the compressional initial motions to the total number of the compressional and the dilatational initial motions could then be obtained. 


\subsection{Microscopic observation of the cracks}

Fluorescence microscopy (Nishiyama and Kusuda, 1994) can be used to visualize cracks and pores in rocks using resin mixed with a fluorescent substance. In the present study, microscopy was performed on the shale samples fractured by injection of viscous oil and water.

To prepare samples for observation, the cores were soaked in the resin for about a week under vacuum and then heat-treated at up to $90^{\circ} \mathrm{C}$ to solidify the resin. Later, cores were cut into sections normal to the crack plane extension induced by hydraulic fracturing and were prepared for observation on a microscope under ultraviolet light. 


\section{Results}

The experiments conducted on the shale cores by testing each of the three hydraulic fracturing fluids under an ambient condition and two uniaxial stresses of 1 and $3 \mathrm{MPa}$. The tests were repeated to confirm the tendency of the results, thus yielding a total of 12 tests. Table 2 summarizes the test results where the last column shows the orientation of the induced cracks in relation with the stress conditions and the used fracturing fluid.

In this section, the results of typical one case for the respective fracturing fluid and loading conditions are shown. The selection of the typical case was made solely on the numbers and quality of the located $\mathrm{AE}$ sources to compare the observed surface cracks. The located AE sources are only those were recorded $1 \mathrm{~s}$ before to $15 \mathrm{~s}$ after the breakdown.

\subsection{Testing observations without loading}

In the experiments of the cores $\mathrm{K}-01$ and $\mathrm{K}-03$, water was used as the fracturing fluid, without loading (0 MPa stress along the Z-axis). Figure 2 shows an example of pressure profile in the hydraulic fracturing test of $\mathrm{K}-03$, the pressure built-up and breakdown occurred at 8.62 MPa. In both of the cores, the crack extended horizontally along a sedimentary plane and was easily traced on the surface of the cores (as in Fig. 3a). The AE events detected by the sensors during the fracturing of the cores were located three-dimensionally. Figure 3b shows AE sources of the core K-03 projected on 
the horizontal plane ( $X-Y$ plane) and the two vertical planes ( $X-Z$ and $Y-Z$ planes). AE sources seen in the vertical planes are distributed in the horizontal direction. These AE results are consistent with the crack trace on the surfaces of the cores.

When a more viscous liquid than water (viscous oil, K-05) was injected, the fracture extended horizontally along the sedimentary bedding, the same propagation as when the fracturing fluid was water. The aperture of the crack induced was noticeably much larger and clearer (Fig. 4a) when the fracturing fluid was oil than when it was water. The projection of the AE source location distribution in $Y-Z$ plane supports the inference of the fracture path from its surface trace (Fig. 4b).

The least viscous fluid $\left(\mathrm{L}-\mathrm{CO}_{2}\right)$ was injected into core Kc-12 under $0 \mathrm{MPa}$ of stress along the $Z$-axis, an intense audible acoustic emission occurred at the moment of breakdown and the fracture extension was not horizontally parallel to the sedimentary planes. This result is unlike the observations recorded for the other fluids, for example the cores K-03 and K-05. Here, the crack extended in a complex inclined direction and a very large aperture that completely split the core was observed on the surface (Fig. 5a). Accordingly, the distribution of AE sources locations (Fig. 5b) showed that the fracture extended at deviated direction of 10 to $30^{\circ}$ from the vertical, which is consistent with the clearly traced fracture on the surface.

\subsection{Testing observations under uniaxial loading}


In the hydraulic fracturing of cores $\mathrm{K}-02$ and $\mathrm{K}-04$ using water as the fracturing fluid, under uniaxial loading of 1 and $3 \mathrm{MPa}$ along the Z-axis, the crack observed on the surface of the cores extended along the loading direction, which was normal to the sedimentary plane. Fig. 6 shows the case of the core K-04 under 3 MPa loading. The both of the cores indicate that the fracture extension was in the loading direction.

When the other cores (K-07 and K-09) were tested using oil as the fracturing fluid under 1 and $3 \mathrm{MPa}$ of stress along the Z-axis, the crack again extended vertically, normal to the sedimentary plane, the same as when the fracturing fluid was water. Fig. 7 shows the case of the core K-09 under 3 MPa loading. The distribution of the AE sources shows that the fracture extended in the vertical direction (Z-axis) in both the $X$ $Z$ and $Y-Z$ planes, which is consistent with the clearly fracture trace on the surface of the cores.

The last experiments were conducted by injecting $\mathrm{L}-\mathrm{CO}_{2}$ in the cores Kc-01, Kc-06 and Kc-07 under $3 \mathrm{MPa}$ of stress along the Z-axis. The cracks observed on the surface of the core Kc-01 extended in two horizontal bedding planes with an inclined crack connecting them though it was under loading. As for the last 2 cores extended in a nearly vertical, but slightly inclined direction as shown in Fig. 8 which is the case of the core Kc-07, unlike in the cores injected with water and oil. The distribution of AE sources locations in $Y$-Z plane (as in Fig. 8b) shows also that the fracture extended at deviated direction from the vertical loading direction. 


\subsection{Analysis of mode of fracturing}

The effect of the difference in fracturing fluid viscosity on the mode of fracturing was examined using the cores tested under $3 \mathrm{MPa}$ of uniaxial loading, K-04 (water), K09 (oil), and $\mathrm{Kc}-07$ ( $\left.\mathrm{L}-\mathrm{CO}_{2}\right)$, because the crack extension under loading seemed to be stable and more clearly affected by fluid viscosity than in the cores without loading, due to the decreasing effect of the sedimentary planes.

To classify the polarities of the P-wave initial motion arrivals as either compressional or dilatational, a polarity calibration test was performed by dropping a steel ball on one side of a steel plate after attaching sensors to the other side. A compressional wave resulted from the impact and radiated from the point of the impact to the sensors attached to the opposite side of the plate. Because the upward trace was recorded in all P-wave initial motion arrivals in this test, the upward trace was recognized and considered as the compressional motion.

The ratio of the compressional to the total initial motions was obtained for 30 large events each for the viscous oil, water, and $\mathrm{L}-\mathrm{CO}_{2}$ injection. The selection of these events was based on the events having at least 12 out of 16 initial motions on the sensors. The analysis revealed that the higher ratios at $60-90 \%$ for the viscous oil injection and at $40-60 \%$ for both the water and the $\mathrm{L}-\mathrm{CO}_{2}$ injections (Fig. 9). The ratio should be $100 \%$ for Mode I fracture (tensile fracture) and should be $50 \%$ for Mode II fracture (in-plane shear fracture). Thus, these results indicate that the injection of 
viscous oil tended to induce Mode I fracture, whereas the injection of water and of L$\mathrm{CO}_{2}$ tended to induce Mode II fracture.

\subsection{Microscopic examination of cracks}

The opening of the crack in the K-05 sample (oil) is somewhat wider than that in the K-03 sample (water), as can be seen by comparing Figs. 3a and 4a. However, there is no marked difference in the fractures between the two samples under loading at 0 $\mathrm{MPa}$, which is probably due to the crack extension running along the sedimentary planes. Comparing the cracks induced under loading at $3 \mathrm{MPa}$ by water and oil, the core K-04, which was fractured by water, contains more inclined cracks having an angle from the loading direction in its path than the core K-09 by oil, (Fig. 10). On the inclined crack surfaces, shear stress develops with the angle, and it becomes the maximum at the angle of 45 degrees to the loading axis. Thus, the crack feature having the inclinations in its path more easily causes shear fracture than that of oil, being consistent with the tendency of fracture mechanism shown in Figure 9. 


\section{Discussion}

We found the following tendency regarding crack extension from the surface crack and AE source distribution observations. In the experiments that used water or oil as the fracturing fluid, cracks tended to extend along the loading direction normal to the sedimentary plane with uniaxial loading and tended to extend along the sedimentary plane if tests were run without loading. The elastic theory indicates that a crack extends in the direction of maximum compressive stress. Thus, the direction of crack extension under uniaxial loading in the present study is consistent with elastic theory. When there was no loading, the crack extended along the weakest plane due to the sedimentary bedding, even though elastic theory indicates that the crack can extend in any direction. These experimental results suggest that the direction of crack extension is strongly affected by in situ stress condition and rock-strength anisotropy. Taking these findings to the field application, if shale strata are horizontally situated and horizontal stress is large, the cracks induced by hydraulic fracturing will tend to extend horizontally. In contrast, when vertical stress is large relative to horizontal stress, for example in a shale stratum at great depth, the cracks will tend to extend vertically, normal to sedimentary planes, and may extend into a different stratum neighboring the shale.

In the experiments using $\mathrm{L}-\mathrm{CO}_{2}$ as a fracturing fluid, crack extension shows an independency of loading condition and the presence of bedding plane unlike in those using water and oil. In addition, even when the same conditions of loading applied, the 
crack extension is different among the cores tested by $\mathrm{L}-\mathrm{CO}_{2}$. The unstable tendency independent of the loading condition might be due to the specific properties of $\mathrm{L}-\mathrm{CO}_{2}$.

The fracture mode can be identified by examining the polarities of P-wave initial motions and obtaining a ratio of the compressional initial motions to a total number of initial motions. The ratio should be $100 \%$ for Mode I fracture (tensile fracture) and 50\% for Mode II fracture (in-plane shear fracture). Thus, our results indicate that the viscous oil injection tends to induce Mode I fracture, whereas both water injection and L-CO injection tend to induce Mode II fracture.

In order to quantify the difference caused by different viscosity, a statistical analysis of the number of branches created by water and oil is carried out. The fractured samples were cut and the section of $8 \mathrm{~mm}$ in length from the injection hole along the crack path is observed by setting 20 scanning lines of $0.4 \mathrm{~mm}$ interval (Fig. 10). By counting the number of fractures that cross the scanning lines (Fig. 11), the injection of oil seems to create branches at only few parts of the crack path, while the water injection creates random number of branches at any point of the crack path. It is noticeable also that the total number of cracks branches resulted by water injection, 55 , is larger than those resulted by oil injection, 38, although this observation is restricted only in the section close to the injection hole.

Furthermore, cracks inclining to the loading direction and branching from a main crack were mainly observed in samples fractured with water. In addition, because shear 
stress develops on an inclined plane with an angle from the loading direction, the difference in the crack feature is consistent with the AE monitoring results that Mode II AE events increased with decrease of the fluid viscosity as shown in Figure 9.

The crack extension in $\mathrm{L}-\mathrm{CO}_{2}$ appeared to be unstable even under the same stress condition. This seems be strongly affected by the difference of fracturing mode due to viscosity of the fracturing fluid, unlike in other fluids, because the viscosity of $\mathrm{L}-\mathrm{CO}_{2}$ is $1 / 10$ and $1 / 2700$ that of water and viscous oil, respectively (see Table 2). Since the slick nature of $\mathrm{L}-\mathrm{CO}_{2}$ makes it easily able to fill even the tiniest spaces, crack extension most likely becomes very sensitive to even small defects in the core. In addition to the low viscosity, the phase of $\mathrm{CO}_{2}$ changes from liquid to gas corresponding to the pressure decrease after crack extension. Since the compressibility of the gas is much larger than that of the liquid, expansion of $\mathrm{CO}_{2}$ gas may help to connect defects inside of a core and cause the fracture to extend in an inclined direction, and also result a much larger sound than that in water or oil injection at the moment of fracture. Ishida et al. (2004; 2012; 2013) previously conducted hydraulic fracturing experiments in granite specimens using carbon dioxide, water, and viscous oil. These studies revealed that low viscosity fluids like $\mathrm{CO}_{2}$ tend to induce widely extending cracks with many branches and with the dominant fracture type being Mode II. The experimental results for the shale cores in the present study seem to be consistent with the tendency observed in granite specimens, particularly with the tendency that crack extension with Mode II dominant fractures 
during $\mathrm{CO}_{2}$ injection is very sensitive to defects, such as tiny spaces in a core. $\mathrm{CO}_{2}$ fracturing, as opposed to conventional slick water fracturing, can likely induce cracks with better features for shale gas production, for example, a larger surface area. In addition, there is a possibility for $\mathrm{CO}_{2}$ to be used for enhance shale gas production and recovery (Kalantari-Dahaghi 2010), because shale's affinity for $\mathrm{CO}_{2}$ is stronger (about 10 times greater) than the affinity for methane (Nuttall 2006) and displacement of absorbed methane (shale gas) with $\mathrm{CO}_{2}$ is expected. .

Taken together, these and past findings suggest that $\mathrm{CO}_{2}$ fracturing is a promising new method for shale gas recovery. 


\section{Conclusion}

The results of this study are as follows:

(1) Surface crack observations and AE source distributions revealed that cracks extended along the loading direction normal to the sedimentary plane under uniaxial loading in the experiments that used water and oil as fracturing fluids. On the other hand, they extended along the sedimentary plane when tests were run without loading. These results suggest that the direction of crack extension is strongly affected by in situ stress condition. However, the $\mathrm{L}-\mathrm{CO}_{2}$ fracturing did not show this tendency, which is probably related to its low viscosity.

(2) The ratio of polarity of P-wave initial motions indicated that injection of viscous oil tends to induce Mode I fracture and both injection of water and injection of $\mathrm{L}-\mathrm{CO}_{2}$ tend to induce Mode II fracture.

(3) Fluorescence microscopy observation revealed that hydraulic fracturing by viscous oil injection produces linear cracks with few branches, whereas hydraulic fracturing by water injection produces cracks with many branches inclining from the loading axis. This is consistent with the differences in fracture mode based on differences in the viscosity of the fracturing fluid, as shown above.

(4) The crack extension after fracturing with $\mathrm{L}-\mathrm{CO}_{2}$ is unlike those after fracturing with other fluids, which seems to be due to the low viscosity of $\mathrm{L}-\mathrm{CO}_{2}$. This result seems to be consistent with the tendency observed by researchers of our group in granite 
specimens, where low-viscosity fluids like $\mathrm{CO}_{2}$ tend to induce widely extending cracks having many branches with Mode II fractures being dominant. This pattern of cracking presents an advantage for shale gas production by fracturing with $\mathrm{L}-\mathrm{CO}_{2}$ over fracturing with conventional slick water. 


\section{Acknowledgment}

The authors wish to acknowledge the kind support of Kushiro Coal Mine Co. Ltd. for providing the shale blocks that were used to prepare the cores for the experiments. 
References

Amadei B, Stephansson O (1977) Rock stress and its measurement. Chapman \& Hall.

Arthur J D, Bohm B, Layne M (2008) Hydraulic fracturing considerations for natural gas wells of the Marcellus shale. Proc. of the ground water protection council annual forum, Cincinnati, Ohio.

Cleary J (1958) Hydraulic fracture theory part II - Fracture orientation and possibility of fracture control. Division of the Illinois state geological survey, circular 252.

Graham C C, Stanchits S, Main I, Dresen G (2010) Comparison of polarity and moment tensor inversion methods for source analysis of acoustic emission data, Int. J. Rock Mech. \& Min. Sci., 47, 161-169.

Haimson B.C. and Cornet F.H. (2003) ISRM Suggested Methods for Rock Stress Estimation-Part 3: Hydraulic Fracturing (HF) and/or Hydraulic Testing of PreExisting Fractures (HTPF). Int. J. Rock Mech. \& Min. Sci., 40, 1011-1020.

Hubbert M, Willis D.G. (1957) Mechanics of Hydraulic Fracturing, Petroleum transactions, AIME.; 210, 153-168.

Ishida T, Chen Q, Mizuta Y, Roegiers J-C (2004) Influence of fluid viscosity on the hydraulic fracturing mechanism, Transactions of the ASME (Journal of Energy Resource Technology) 126: 190-200. 
Ishida T, Aoyagi K, Niwa T, Chen Y, Murata S, Chen Q, Nakayama Y (2012) Acoustic emission monitoring of hydraulic fracturing laboratory experiment with supercritical and liquid CO2, Geophysical Research Letters 39: L16309. doi:10.1029/2012GL052788

Ishida T, Nagaya Y, Inui S, Aoyagi K, Nara Y, Chen Y, Chen Q, Nakayama Y. (2013) AE monitoring of hydraulic fracturing experiments with $\mathrm{CO}_{2}$ and water, Proc. of Eurock2013, Wroclaw, Poland, 957-962.

Kalantari-Dahaghi A (2010) Numerical simulation and modeling of enhanced gas recovery and $\mathrm{CO}_{2}$ sequestration in shale gas reservoirs: A feasibility study, Proc. of International Conference on $\mathrm{CO}_{2}$ Capture, Storage, and Utilization, Soc. of Pet. Eng., New Orleans, La.

Nishiyama T, Kusuda H (1994) Identification of pore spaces and micro cracks using fluorescent resins, Int. J. Rock Mech. Min. Sci. \& Geomech. Abstr. 31(4): 369-375.

Nuttall BC (2006) Sequestration in gas shale of Kentucky, Proc of 5th Annual Conference on Carbon Capture and Sequestration, Alexandria, Virginia, USA, Poster No. 106.

Schmitt D.R., Zoback M.D., (1989) Poro-elastic effects in the determination of the maximum horizontal principal stress in hydraulic fracturing tests-a proposed breakdown equation employing a modified effective stress relation for tensile failure. International 
Journal of Rock Mechanics, Mining Sciences and Aeromechanics. Abstr ;26:499-506. Pergamon Press.

Sun K, Tan J, Wu D (2011) The research on dynamic rules of crack extension during hydraulic fracturing for oil shale in-situ exploitation. International conference on environmental science and engineering (ICESE 2011). Procedia Environmental Sciences 12 ( 2012 ) 736 - 743. Elsevier.

Zang A, Wagner F C, Stanchits S, Dresen G, Andresen R, Haidekker M A (1998) Source analysis of acoustic emissions in Aue granite cores under symmetric and asymmetric compressive loads, Geophys. J. Int., 135, 1113-1130.

Zang A, Stephansson O (2010) Stress field of the earth's crust. ISBN 978-1-4020-84447. Springer.

Zoback M D, Rummel F, Jung R, Raleigh C B (1977) Laboratory hydraulic fracturing experiments in intact and pre-fractured rock, Int. J. Rock Mech. Min. Sci. \& Geomech. Abstr., 14, 49-58. 


\section{Figure captions}

Figure 1 Diagram and photograph of the core dimensions and coordinates.

Figure 2 Test profile for shale core K-03 (water) under 0 MPa loading.

Figure 3 (a) Photograph with magnification of observed crack (red box) on the surface and (b) AE source locations in core K-03 under $0 \mathrm{MPa}$ loading and injection with water.

Figure 4 (a) Photograph with magnification of observed crack (red box) on the surface and (b) AE source locations in core K-05 under 0 MPa loading and injection with oil.

Figure 5 (a) Photograph of observed crack (red box) on the surface and (b) AE source locations in core Kc-12 under $0 \mathrm{MPa}$ loading and injection with $\mathrm{L}_{-} \mathrm{CO}_{2}$.

Figure 6 (a) Photograph of observed crack (red box) on the surface and (b) AE source locations in core K-04 under 3 MPa loading and injection with water.

Figure 7 (a) Photograph of observed crack (red box) on the surface and (b) AE source locations in core K-09 under 3 MPa loading and injection with oil.

Figure 8 (a) Photograph of observed crack (red box) on the surface and (b) AE source locations in core Kc-07 under $3 \mathrm{MPa}$ loading and injection with $\mathrm{L}-\mathrm{CO}_{2}$.

Figure 9 Polarity ratios of compressional initial motions in $30 \mathrm{AE}$ events for each hydraulic fracturing experiment using viscous oil, water, and $\mathrm{L}-\mathrm{CO}_{2}$.

Figure 10 Fluorescence microscopy of the crack shape after (a) injection of water into core K-04 and (b) injection of oil into core K-09. In the both photos, the cracks propagated across the sedimentary planes from the injection hole, which is located in 
the lower end of the photos. The lines of $0.4 \mathrm{~mm}$ interval are scanning lines to count numbers of crack branches shown in Figure 11.

Figure 11 Comparison between the numbers of crack branches made by water and viscous oil at the same distance. 


\section{Table captions}

Table 1 Anisotropy of P-wave velocity in shale cores

Table 2 Summary of the main experimental results 
Table 1 Anisotropy of P-wave velocity in shale cores

\begin{tabular}{cccc}
\hline & \multicolumn{3}{c}{ P-wave velocity $(\mathrm{km} / \mathrm{s})$} \\
Core & $X$ & $Y$ & $Z$ \\
\hline K-01 & 3.23 & 3.11 & 3.55 \\
K-03 & 3.12 & 3.13 & 2.75 \\
K-04 & 3.24 & 3.24 & 2.92 \\
K-05 & 3.65 & 3.36 & 2.28 \\
K-07 & 3.00 & 3.11 & 2.84 \\
K-09 & 2.80 & 3.50 & 2.87 \\
Kc-01 & 3.20 & 3.30 & 2.90 \\
Kc-06 & 3.36 & 3.19 & 3.10 \\
Kc-07 & 3.28 & 3.28 & 3.01 \\
Kc-12 & 3.59 & 3.73 & 3.82 \\
\hline
\end{tabular}

Table 2 Summary of the main experimental results

\begin{tabular}{|c|c|c|c|c|c|c|}
\hline Core & $\begin{array}{l}\text { Loading stress } \\
\sigma \mathrm{z}(\mathrm{MPa})\end{array}$ & $\begin{array}{l}\text { Fracturing fluid } \\
\text { (viscosity, } \mathrm{mPa} \cdot \mathrm{s} \text { ) }\end{array}$ & $\begin{array}{l}\text { Injection rate } \\
(\mathrm{ml} / \mathrm{min})\end{array}$ & $\begin{array}{l}\text { Breakdown } \\
\text { (MPa) }\end{array}$ & $\begin{array}{c}\text { Located } \\
\text { (Detected) } \\
\text { AE sources }\end{array}$ & Fracture orientation \\
\hline K-01 & 0.0 & water (1) & 1.00 & 5.24 & $13(122)$ & Parallel to bedding \\
\hline K-03 & 0.0 & water (1) & 1.00 & 8.62 & $32(72)$ & Parallel to bedding \\
\hline K-02 & 1.0 & water (1) & 1.00 & 13.08 & $22(160)$ & Loading direction \\
\hline K-04 & 3.0 & water (1) & 1.00 & 16.44 & 65 (205) & Loading direction \\
\hline K-05 & 0.0 & oil (270) & 1.00 & 9.95 & $26(91)$ & Parallel to bedding \\
\hline K-07 & 1.0 & oil (270) & 1.00 & 8.86 & $62(244)$ & Loading direction \\
\hline K-09 & 3.0 & oil (270) & 1.00 & 8.86 & 39 (319) & Loading direction \\
\hline Кс-01 & 3.0 & $\mathrm{~L}-\mathrm{CO}_{2}(0.10)$ & 1.00 & 6.91 & 36 (336) & Different direction \\
\hline Kc-06 & 3.0 & $\mathrm{~L}-\mathrm{CO}_{2}(0.10)$ & 1.00 & 6.81 & $0(41)$ & Different direction \\
\hline Кс-07 & 3.0 & $\mathrm{~L}-\mathrm{CO}_{2}(0.10)$ & 1.00 & 6.08 & $42(169)$ & Different direction \\
\hline Kc-12 & 0.0 & $\mathrm{~L}-\mathrm{CO}_{2}(0.10)$ & 1.00 & 8.12 & 55 (245) & Different direction \\
\hline
\end{tabular}


Figure 1 Diagram and photograph of the core dimensions and coordinates.

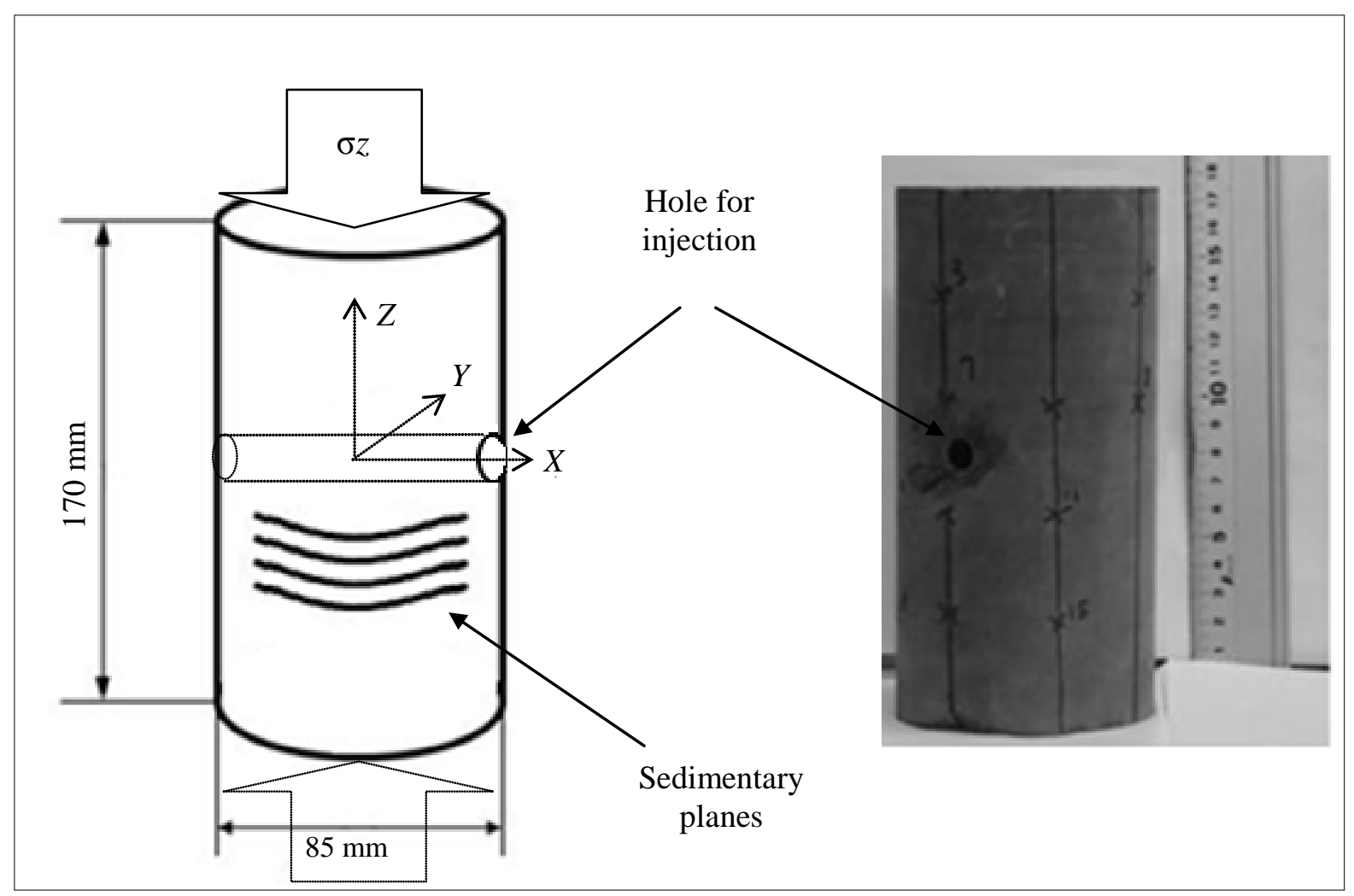


Figure 2 Test profile for shale core K-03 (water) under 0 MPa loading.

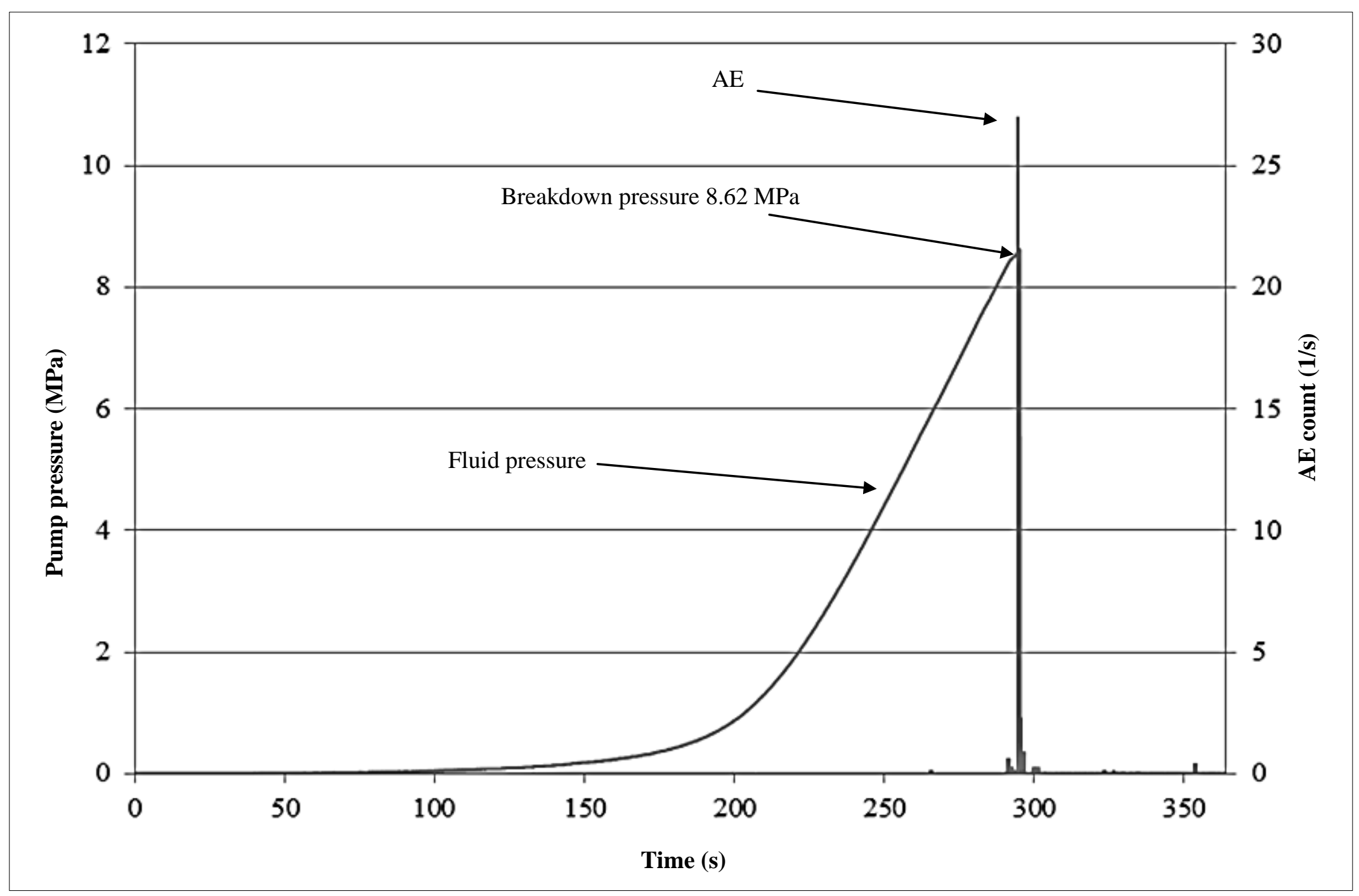


Figure 3 (a) Photograph with magnification of observed crack (red box) on the surface and (b) AE source locations in core K-03 under $0 \mathrm{MPa}$ loading and injection with water.
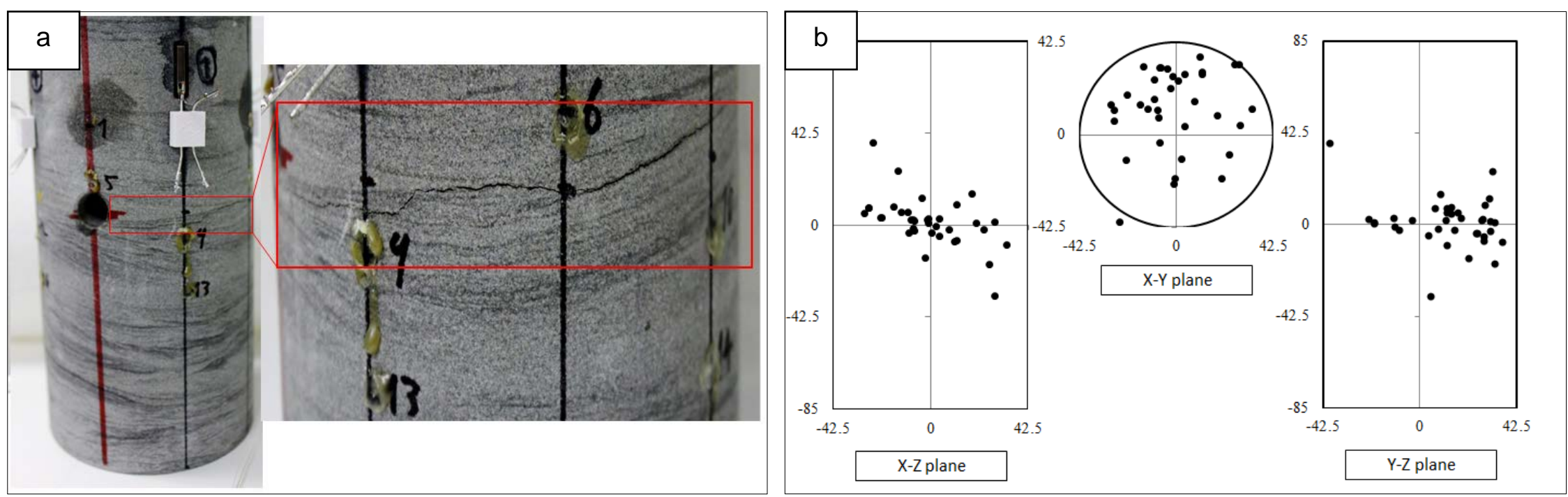
Figure 4 (a) Photograph with magnification of observed crack (red box) on the surface and (b) AE source locations in core K-05 under $0 \mathrm{MPa}$ loading and injection with oil.
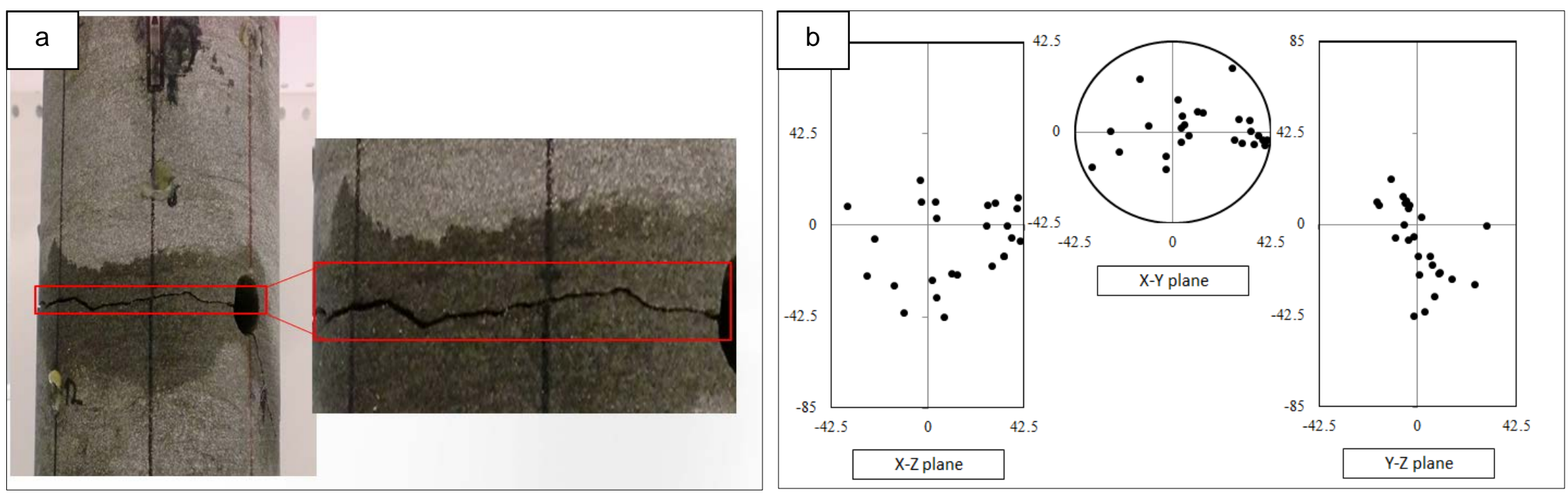
Figure 5 (a) Photograph of observed crack (red box) on the surface and (b) AE source locations in core Kc-12 under 0 MPa loading and injection with L-CO2.
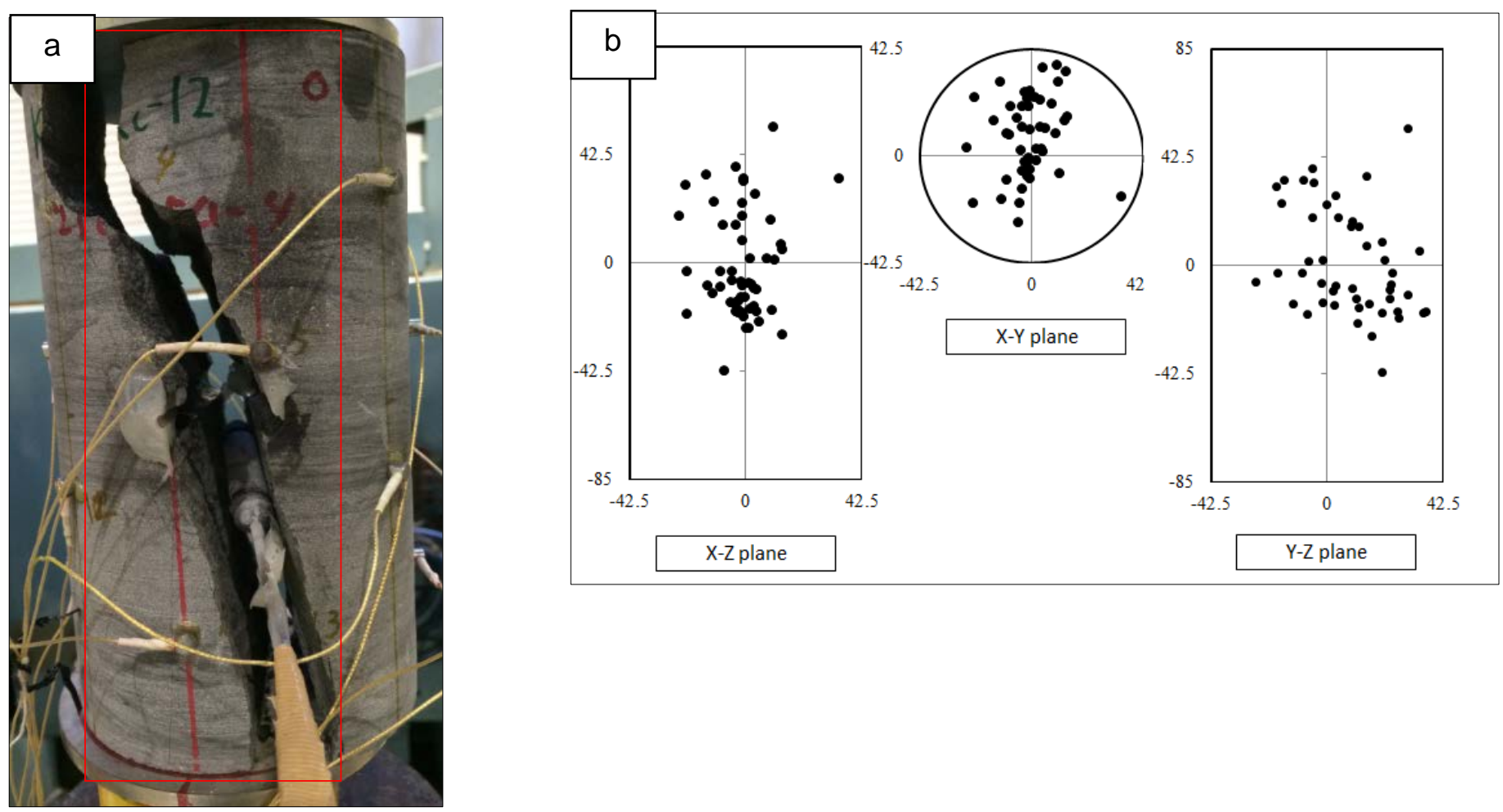
Figure 6 (a) Photograph of observed crack (red box) on the surface and (b) AE source locations in core K-04 under 3 MPa loading and injection with water.
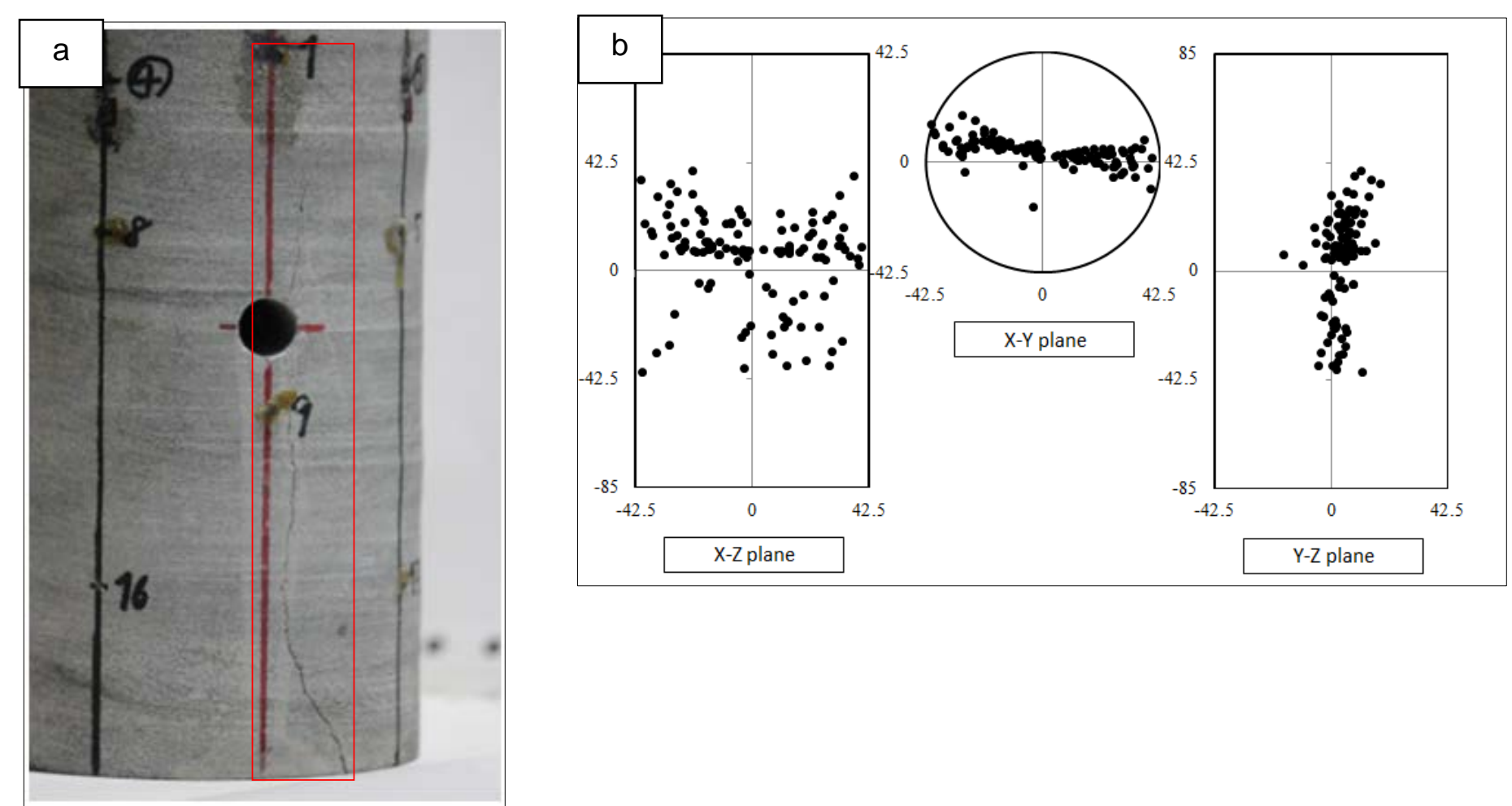
Figure 7 (a) Photograph of observed crack (red box) on the surface and (b) AE source locations in core K-09 under 3 MPa loading and injection with oil.
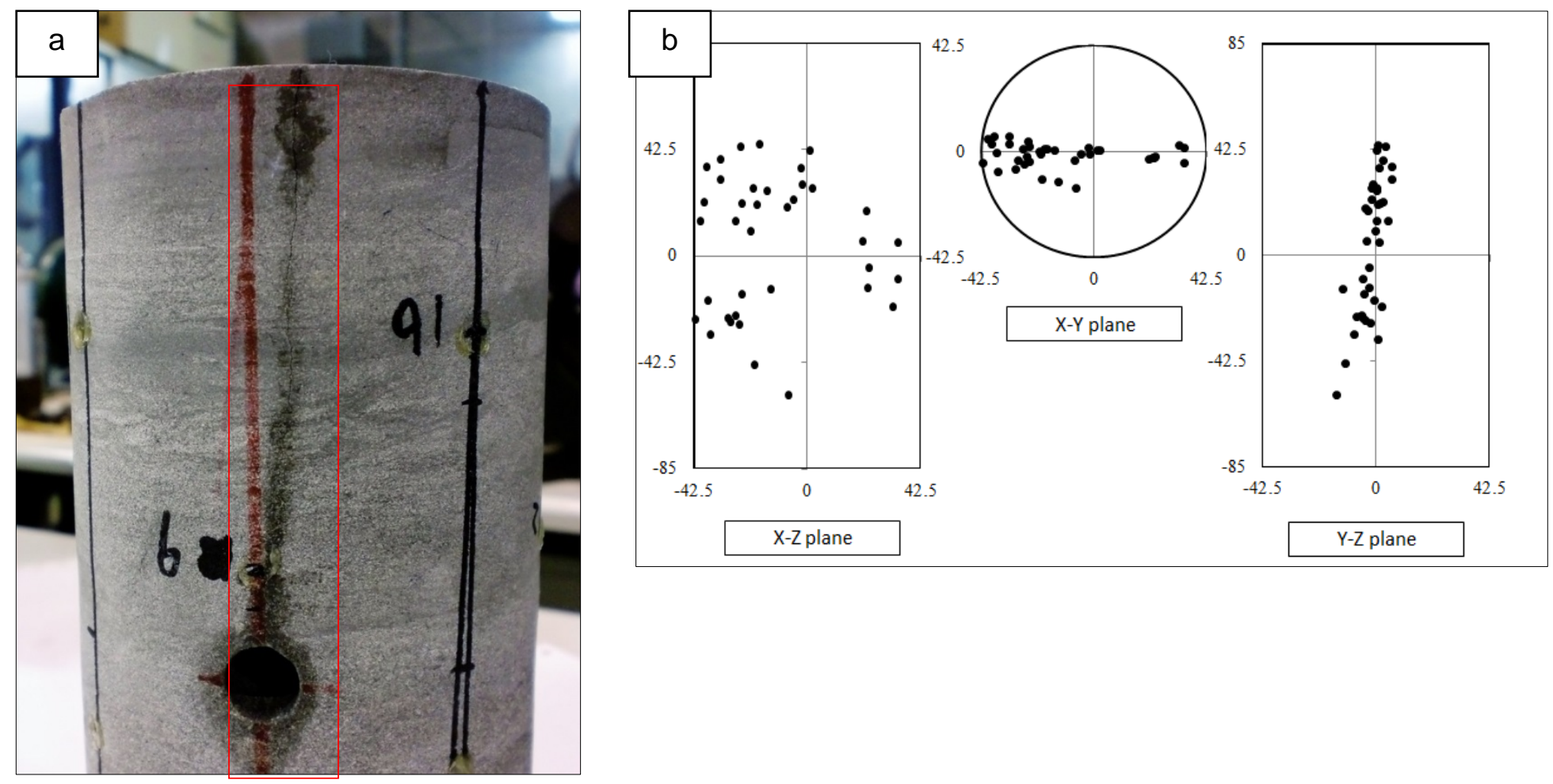
Figure 8 (a) Photograph of observed crack (red box) on the surface and (b) AE source locations in core Kc-07 under 3 MPa loading and injection with L-CO2.
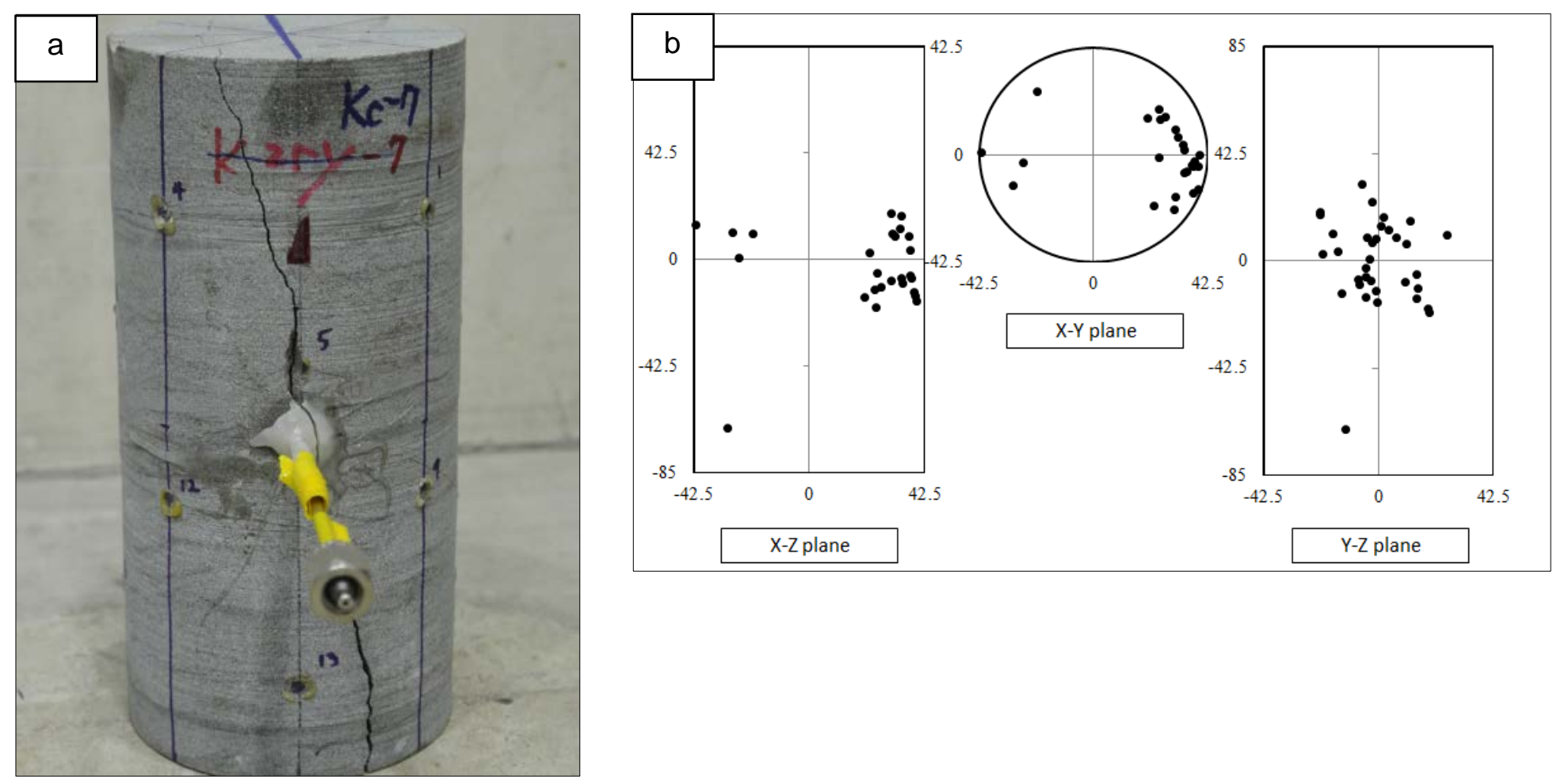
Figure 9 Polarity ratios of compressional initial motions in 30 AE events for each hydraulic fracturing experiment using viscous oil, water, and L-CO2.

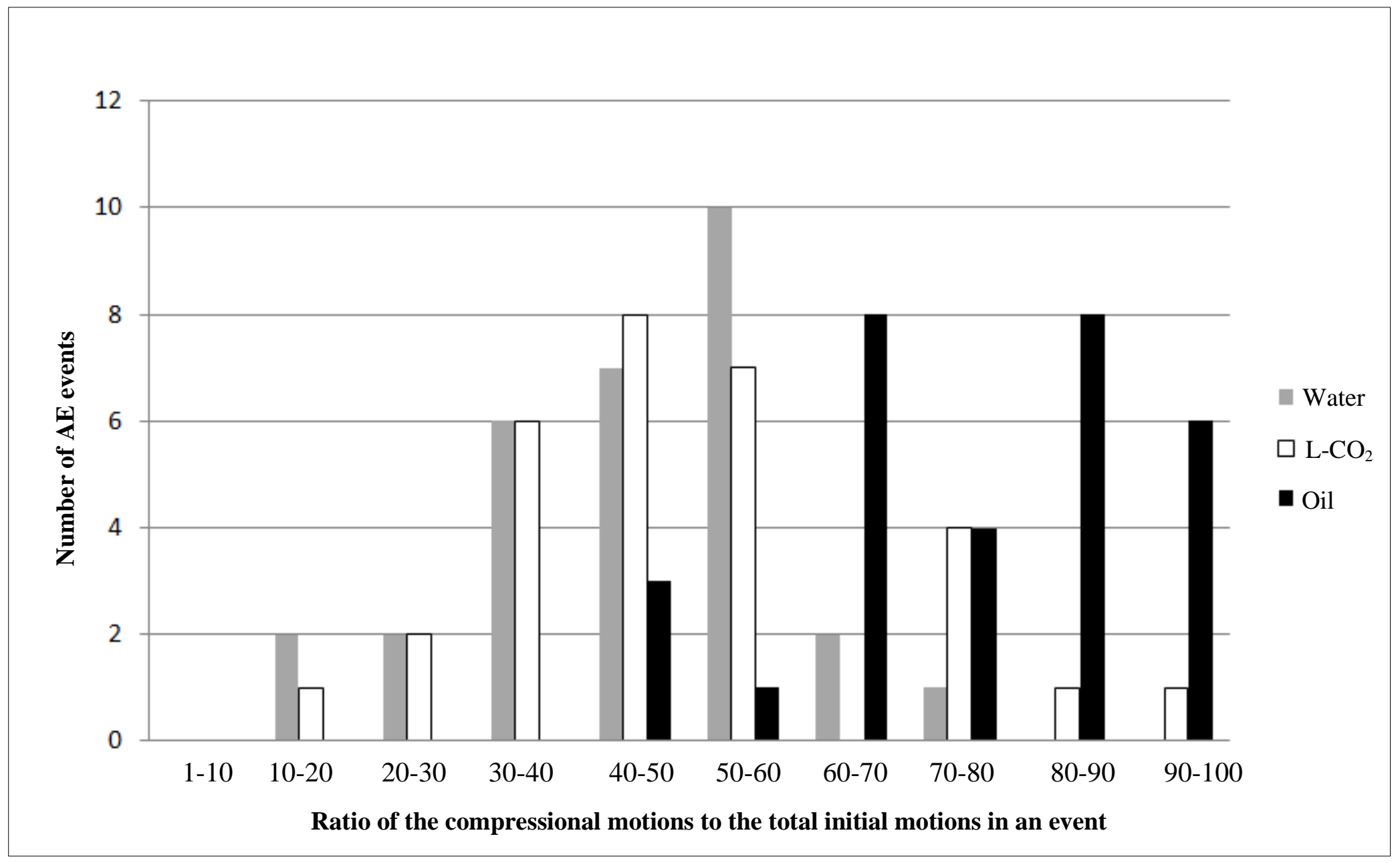


Figure 10 Fluorescence microscopy of the crack shape after (a) injection of water into core K-04 and (b) injection of oil into core K-09. In the both photos, the cracks propagated across the sedimentary planes from the fracturing hole, which is located in the lower end of the photos. The lines of $0.4 \mathrm{~mm}$ interval are scanning lines to count numbers of crack branches shown in Figure 11.

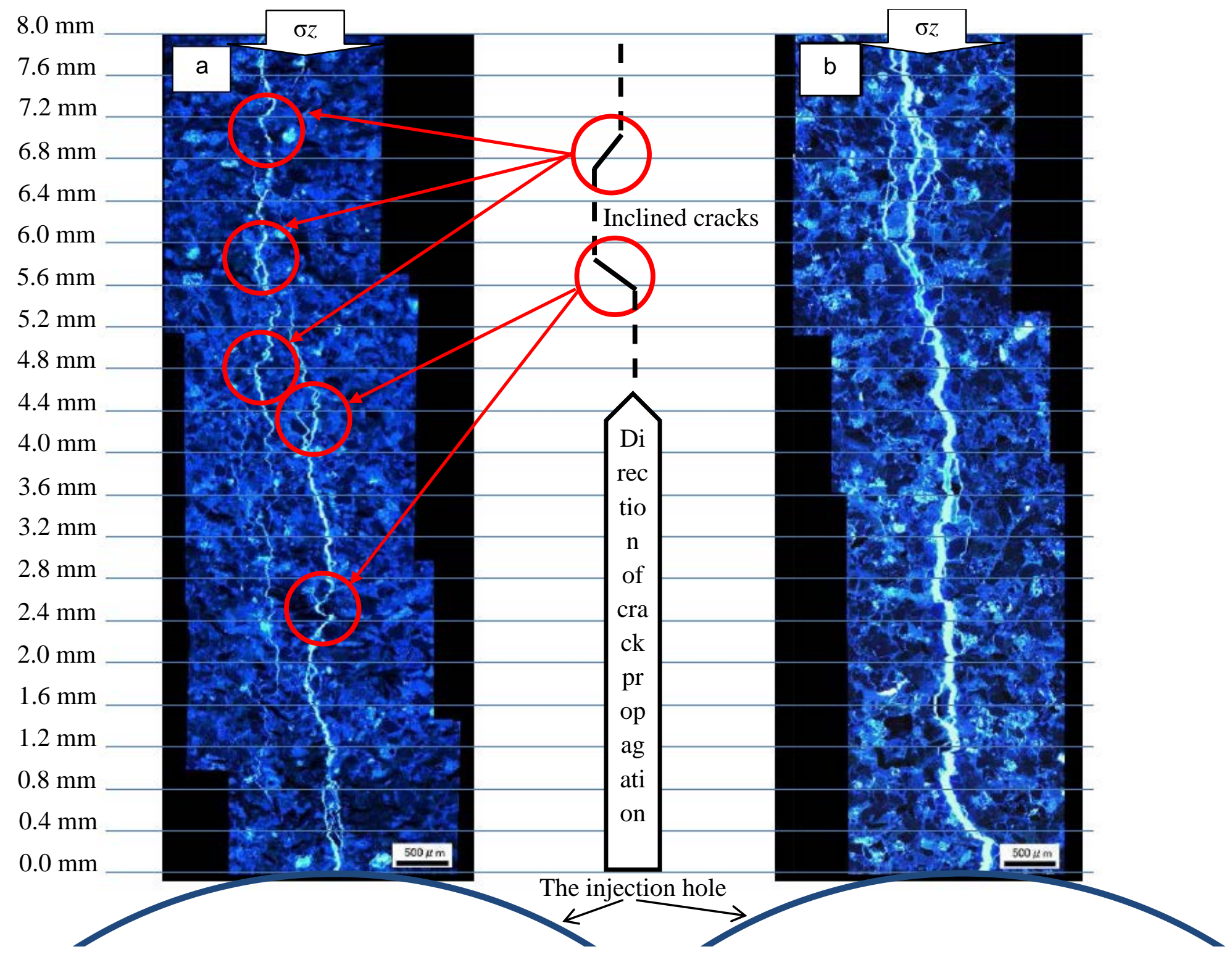


Figure 11 Comparison between the numbers of crack branches made by water and viscous oil at the same distance.

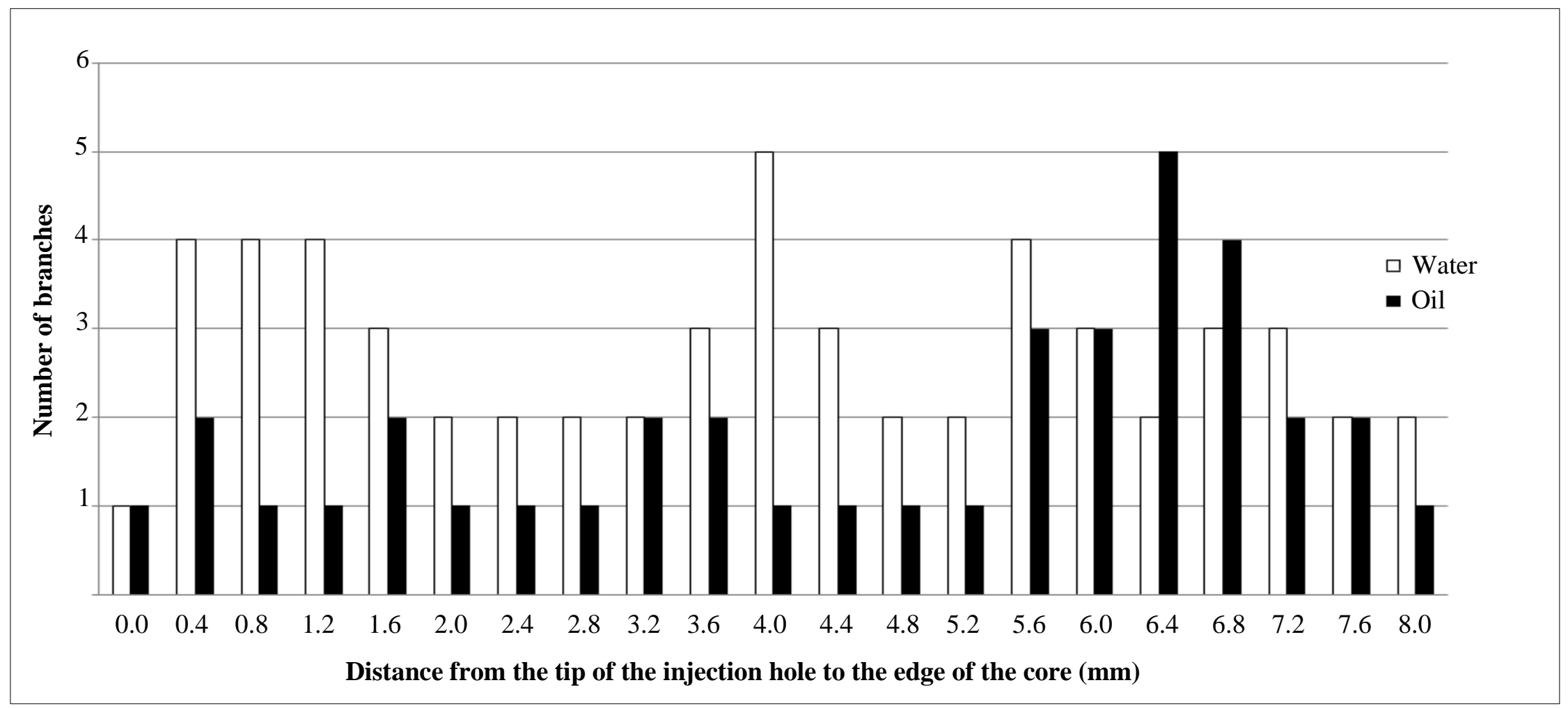

